\title{
INCLUSÃO: UM CAMINHO QUE PRECISA SER PERCORRIDO
}

\author{
INCLUSION: A PATH THAT NEEDS TO BE TAKEN \\ Madson Márcio de Farias Leite ${ }^{2}$ \\ Clara Roseane da Silva Azevedo Mont'Alverne ${ }^{3}$
}

\begin{abstract}
RESUMO: A Educação Especial perpassou por diversos caminhos para se chegar ao processo da inclusão no tocante a sua garantia de direitos segundo as leis e políticas públicas que asseguram sua oficialização. Nem sempre foi assim, a inclusão vem acontecendo de modo gradativo nos dias atuais, sendo que ainda existe um longo processo para que a inclusão para todos possa se tornar efetiva tal qual está escrito nas leis que a garantem. A pesquisa tem como objetivo trazer um estudo sobre a inclusão como sendo um caminho que precisa ser percorrido, já que não se consegue ser pertencente e se sentir incluso sem antes percorrer e passar por várias etapas até o processo da inclusão ser efetivado. A pesquisa trouxe como metodologia a pesquisa bibliográfica, onde foi realizado um levantamento em artigos e trabalhos já publicados que retratassem do processo percorrido para se chegar ao tão esperado método inclusivo. A inclusão sempre foi percebida como algo não muito importante ao longo dos anos, isso foi devido que apenas uma pequena parcela da população chegava a procurar seus direitos, e fazer com que os documentos que legalizavam a inclusão fossem realmente efetivados, as pesquisas e estudos realizados na área da inclusão possibilitou que uma grande parcela de pessoas com alguma deficiência pudessem lutar e reivindicar por direitos até antes negados. A pesquisa concluiu que os avanços tecnológicos, as políticas públicas, as leis e a luta de toda uma sociedade proporcionaram que a inclusão mesmo sendo necessário percorrer um longo caminho, ela pode de fato ocorrer e beneficiar na vida das pessoas que nasceram ou foram acometidas ao longo do tempo por alguma deficiência. E assim, passando a ser enfatizado e desmistificado como aquilo que parecia ser algo inalcançável, passasse a ser efetivado e ganhasse credibilidade de escolas, família e demais espaços públicos como sendo obrigados a reconhecer e aceitar, como também tendo que se capacitarem para poder fazer valer a garantia de todos os direitos inerentes aos sujeitos com deficiência ao longo de toda a sua vida, isso independentemente de onde eles venham querer estar ou permanecer. E dessa forma propiciar na vida desses sujeitos um desenvolvimento de todas as suas potencialidades, através de técnicas e métodos inovadores para alcançarem a equiparação aos outros sujeitos sem nenhuma deficiência específica.
\end{abstract}

Palavras- chave: Inclusão. Deficiência. Garantia de direitos. Educação.

ABSTRACT: Special education has gone through several paths to reach the inclusion process with respect to its guarantee of rights under the laws and public policies that ensure its officialization. This has not always been the case, inclusion has been happening gradually nowadays, and there is still a long process for inclusion for all to become effective as written in the laws that guarantee it. The research aims to bring a study on inclusion as a path that needs to be taken, since you cannot belong and feel included without first going through and going through several stages until the inclusion process is completed. The research brought bibliographic research as a methodology, where a survey was carried out on articles and works already published that portrayed the process followed to arrive at the long-awaited inclusive method. Inclusion has

'Este artigo foi construído a partir da fundamentação teórica e reflete dados bibliográficos parciais da Tese em construção em Ciências da Educação pela Universidad Autónoma de Asunción - UAA, Paraguai - (Py). ${ }^{2}$ Doutorando em Ciências da Educação pela Universidad Autónoma de Asunción - UAA, Paraguai - (Py). E-mail: madsonmarcio@hotmail.com.

3 Orientadora do artigo. Doutora em Ciências da Educação pela Universidad Autónoma de Asunción - UAA, Paraguai-(Py). E-mail: clarazevedo@globo.com. 
always been perceived as something not very important over the years, this was due to the fact that only a small portion of the population came to seek their rights, and to make the documents that legalized the inclusion were actually carried out, the research and studies carried out in the area of inclusion, it enabled a large portion of people with a disability to fight and claim rights that had previously been denied. The research concluded that technological advances, public policies, laws and the struggle of an entire society provided that inclusion, even though it is necessary to go a long way, it can actually occur and benefit in the lives of people who were born or were affected by over time for some disability. And so, starting to be emphasized and demystified as what seemed to be something unattainable, it became effective and gained credibility from schools, family and other public spaces as being obliged to recognize and accept, as well as having to train themselves to be able to assert themselves the guarantee of all the rights inherent to subjects with disabilities throughout their lives, regardless of where they come to want to be or stay. And in this way to provide in the life of these subjects a development of all their potentialities, through innovative techniques and methods to achieve equivalence with other subjects without any specific deficiency.

Keywords: Inclusion. Deficiency. Guarantee of rights. Education.

\section{INTRODUÇÃO}

O processo da educação especial, na perspectiva da educação inclusiva, veio ao longo dos tempos passando por vários avanços, sendo estes de forma muito gradativa, uma vez que esta política pública acabou fazendo com que determinado processo (que ao longo dos anos sempre foi percebido como algo não importante por se tratar de uma pequena parcela da sociedade), se tornasse fonte de estudos e pesquisas em prol de uma causa que até antes não precisava ou não era possível.

Através dos avanços tecnológicos e comprovações através de experimentos, pôde-se perceber que aqueles que foram marginalizados durante séculos, podiam aprender mesmo que vagarosamente, uma vez que seu baixo nível cognitivo ou mobilidade física não era superior a força de vontade e ensino adequado para fazer com que esse sujeito não tivesse nenhum aprendizado. Desse modo, o processo foi sendo desmistificado como algo inalcançável, ganhando cada vez mais credibilidade devido a todas as pesquisas e leis que reforçaram esse processo, para que o mesmo fosse assim garantindo sua efetivação mesmo que por ordem judicial.

Ao se falar sobre inclusão, logo se remete ao processo educacional, sendo este apenas um deles, não podendo esquecer que inclusão é algo que garanta a qualquer pessoa com deficiência ser inserida de forma igual em qualquer ambiente que a mesma venha pertencer ou permanecer. Sendo assim, a inclusão quando voltada ao ambiente escolar ganha mais espaço, por se tratar do processo de formação do sujeito, contribuindo assim de forma integral no processo de formação, tanto da sua personalidade como de sua identidade. 
A pesquisa tem como objetivo trazer um estudo sobre a inclusão como sendo um caminho que precisa ser percorrido, diante das limitações impostas pela sociedade e contextos sociais as quais as pessoas com alguma deficiência vêm ser inserida. Dessa forma se faz necessário além de percorrer um caminho longo, fazer valer através de lutas, a efetivação dos direitos adquiridos em lei.

O estudo pôde fazer valer de uma metodologia de pesquisa bibliográfica, buscando através de artigos e trabalhos científicos já publicados que retratassem da temática do longo percurso necessário a ser percorrido para se chegar a efetivação e garantia da inclusão. Ao se falar em inclusão já nos remetemos ao contexto educacional, porém a inclusão está relacionada a garantia de direitos e pertencimento independente de qual seja o espaço escolhido

Portanto, o referido estudo trouxe contribuições no tocante a sistematização de informações, e referências do longo caminho a ser percorrido para se conseguir a garantia dos direitos ao processo inclusivo. E não deixando com que todos os direitos inerentes a toda uma população que venha necessitar de garantia para que estes sejam efetivados, não percam ou sejam esquecidas por uma parcela da população, e levando ao descaso e reconhecimento da tão importância de que é a inclusão na vida daqueles que dela venham precisar ao longo de sua existência.

No que se refere a relevância, o estudo pôde descrever através do levantamento de informações que a inclusão é um processo alcançável, podendo assim enfatizar que o sucesso do processo só será possível através de um viés de grande significado que é a educação, e assim, podendo descrever e alcançar todos os sujeitos independente de qual seja seu défice, e com isso podendo proporcionar um desenvolvimento de forma integral na vida dessas pessoas. Uma vez que só a educação é possível de fazer com que a inclusão deixe de ser algo que necessite perpassar por vários caminhos e lutas para que a mesma possa ser garantida a todos.

A inclusão em conjunto com a educação pode fazer a transformação tanto no processo de aceitação, como no viés da garantia de permanência e aprendizado de todos aqueles que venham recorrer desse sistema de desenvolvimento, para assim se desenvolver e se sentir pertencente de fato a todos de forma análoga. 


\section{O Processo de inclusão sendo iniciado pelo espaço escolar}

O espaço escolar é tido como mais um ambiente em que deve ocorrer de fato o processo da inclusão, já que esse acesso e permanência são garantidos constitucionalmente, como também assegurados por várias leis e decretos, que contribuem para a segurança de todos aqueles que nascem com (ou adquirem) algum tipo de deficiência, de permanecer de forma inclusiva dentro do espaço escolar, opondo-se à construção histórica que ao longo do tempo contribuiu para a segregação e a perpetuação do preconceito.

É oportuno considerar, por exemplo, a afirmação de (DINIZ, 2012, p. I2), ao constatar que:

\footnotetext{
A concepção de deficiência como uma variação do normal da espécie humana foi uma criação discursiva do século XVIII, e desde então ser deficiente é experimentar um corpo fora da norma. O corpo com deficiência somente se delineia quando contrastado com uma representação de o que seria o corpo sem deficiência. Ao contrário do que se imagina, não há como descrever um corpo com deficiência como anormal. A anormalidade é um julgamento estético e, portanto, um valor moral sobre os estilos de vida.
}

Essa foi uma concepção utilizada e designada durante muito tempo para com as pessoas com deficiência, visto que ser deficiente era tido como sinônimo de incapacidade. Nesse sentido, a sociedade por si só acabava estipulando o que seria normal e aceitável para permanecer ou fazer parte de determinados grupos sociais.

Ao longo do tempo, esse conceito de que ser deficiente era algo fora da normalidade foi sendo diminuído, no que se refere a questões explícitas de atitudes preconceituosas a todos aqueles que tinham alguma deficiência. Com isso, as políticas públicas e algumas manifestações sociais fizeram com que alguns representantes governamentais se mobilizassem em prol desta causa.

Diniz (2012) destaca também que esses sujeitos por viverem à margem da sociedade sem respeito, nunca tendo direitos de atendimentos especializados, acabaram sendo alvo de atitudes preconceituosas e ações impiedosas aplicada por todas as partes e dos diversos órgãos e espaços da sociedade, sendo um deles o meio escolar.

Com o passar dos anos, a humanidade acabou reformulando e se adaptando a conviver e entender como se dava o processo da inclusão social, fazendo com que houvesse algumas modificações relacionadas ao modo de pensar, viver e se relacionar com os ditos 
diferentes por uma parcela da sociedade, fazendo assim com que algumas pessoas os excluíssem e os tratassem como diferentes de todas as partes da sociedade. Algumas vezes, escondia-se e se depreciava aqueles que em sua maioria não sabiam se defender nem tão pouco lutar e exigir seus direitos (CARVALHO, 2019).

Aos poucos, foram sendo propostas determinadas regras e condições, uma delas seria a igualdade pela diferença. De certo modo, isso impôs formas de legalizar direitos e punir legitimamente repartições e espaços que não se adequassem a receber e tratar todos com a mesma igualdade dada a qualquer sujeito, independentemente de sua mobilidade e especificidade.

Com o avanço das ciências como no caso a psicologia, e o aumento da taxa de natalidade, aconteceram algumas modificações e formas de tratamento e inclusão das pessoas com algum tipo de deficiência. Os efeitos dessas mudanças foram satisfatórios no que se refere a uma melhor forma de se integrar e buscar assim incluir esses sujeitos, já que a falta da integração dessas pessoas na sociedade de forma global acabava afastando-as de viver plenamente de forma semelhante a todos aqueles sem nenhuma deficiência (JANNUZZI, 2017).

"No caso da psicologia, vê-se um avanço no que se refere a métodos e técnicas de ensino-aprendizagem, como também na utilização de testes psicológicos como forma de ajudar a todos aqueles com algum tipo de deficiência mental” (JANNUZZI, 2017, p. I9). Desta forma, podem-se buscar meios de como contribuir nesse processo de desenvolvimento como também na parte do ensino-aprendizagem destes sujeitos, interferindo e buscando alternativas e formas de ensinamentos adequados para que possa de fato haver um aprendizado de forma significativa na vida destes sujeitos.

No Brasil houve alguns avanços significativos na década de 1990, e início do século XXI no que se refere a estudos e uma maior intensificação de cursos e pós- graduação no âmbito da educação especial. Oliveira (2015) destaca que a educação especial no Brasil começou a se propagar através de ações e diretrizes que viabilizavam um aumento nos estudos e formação de pessoas para ensinar e preparar sobre como lidar com o processo de inclusão. Tal processo aparentava ser simples, mas na sua efetivação acabou deixando toda uma população confusa e sem nenhuma habilidade para proporcionar e ensinar como ocorria e se desenvolveria o processo de inclusão social. 
As leis brasileiras como a LDB 9394/96 foram fundamental no que se refere à legalização e implementação das garantias de direitos, um deles a participação ativa na sociedade. Desse modo de forma gradual foi possível resgatar dentro destes contextos sociais, a dignidade da pessoa humana, uma vez que a garantia imposta pela lei faz com que esses sujeitos possam usufruir de forma igual a todos os demais indivíduos.

Um dos benefícios adquiridos com a garantia dos direitos é uma melhor qualidade de vida, já que anteriormente estes viviam segregados, como também de forma degradante e desumana impedidos de viver de forma plena dentro da sociedade. Ao adquirir alguns direitos essa população pôde de fato alcançar um desenvolvimento melhor no que se refere ao nível cognitivo, e poder aprender já que as chances eram distribuídas e vivenciadas por todos igualmente, e assim obtendo um melhor desempenho com relação ao aprendizado Morais e Oliveira (2017).

Contudo ainda hoje ao se falar o termo deficiência, ainda ocorre estranhamento e repulsão por uma parcela da sociedade. Isso ocorre porque o processo de inclusão de pessoas com deficiências dentro de todos os ambientes da sociedade nunca foi algo aceito nem tido como normal.

Mas os sujeitos com deficiência começaram a buscar e a lutar por seus direitos, e assim fizeram com que a sociedade passasse a discutir a sua inserção em diversos espaços. Com isso, começou-se a perceber que, mesmo com sua deficiência, esses sujeitos têm muito que ensinar como sujeitos pensantes e ativos dentro de uma sociedade Morais e Oliveira (2017).

\footnotetext{
Para conquistarmos uma sociedade inclusiva, uma escola inclusiva, devemos começar por nós mesmos. Através de nossas ações cotidianas, no dia-a-dia da escola, da sala de aula. Divulgando nossas vivências, nossos erros, acertos, nossos encontros e desencontros, não tendo vergonha de não saber e de aprender com o aluno, com suas dificuldades e possibilidades (MORAIS e OLIVEIRA, 2017, p. 17).
}

Sabe-se que as dificuldades enfrentadas e vividas no dia a dia por aqueles que trazem consigo algum tipo de deficiência são inúmeras, já que estas vão se utilizarem do meio para se deslocar até a comunicação e aprendizado de forma geral, fazendo com que mesmo com todo o aparato legal que exista no Brasil e no mundo, esses sujeitos vivam em uma sociedade de forma diferenciada. Desse modo, os direitos são enfatizados pela Constituição comum a todos, no entanto, na prática essa política pública acaba falhando na hora da sua efetivação. 
De acordo com o Morais e Oliveira (2017) esse passo para que o processo de inclusão possa ocorrer é algo que parte de cada um. No que se refere às nossas ações desenvolvidas diariamente e vividas por cada ser humano, pode-se divulgar e enfatizar a inclusão como algo imposto por direito. Portanto, deve-se contribuir nesse processo no que se refere a atitudes e formas de agir diante de situações que coloque como contribuintes nesse processo que acaba sendo dificultado por toda uma população, às vezes por falta de preparo e conhecimento da causa.

\section{Inclusão: um direito de todos}

Ao se mencionar a inclusão como sendo uma das garantias aludidas constitucionalmente, esta deve ser assegurada de forma condizente a todos, uma vez que, o termo inclusão e sua implantação devem se referir em todos os aspectos no que menciona ser de forma igualitária a todos os sujeitos independentes de ter ou não alguma mobilidade. Já que é tido como direito de todos, este não deve ser restrito apenas a uma pequena parcela da população.

A educação se apresenta como um desses direitos que devem ser assegurados a todos democraticamente e reconhecido ao longo dos tempos como de essencial contribuição para o processo de aprendizagem e formação social do ser humano. Em virtude desse direito sempre ter sido restrito àqueles que não possuíam nenhuma deficiência, a contribuição da luta dos direitos humanos foi importante para que o acesso e permanência de qualquer sujeito no meio social fossem garantidos.

Como dito anteriormente, a partir da Declaração Universal dos Direitos Humanos DUDH de 1948, ONU (1948), começou uma grande mudança no que se refere ao comportamento mundial sobre o tratamento aludido a todos aqueles que tinham algum tipo de deficiência, já que esse público era um dos mais prejudicados no que se refere à igualdade de direitos.

Através da educação tais direitos buscam proporcionar um legado de informação a todos, para que assim possam lutar e exigir dos órgãos competentes o cumprimento das políticas públicas que garantam a ascensão e a igualdade de permanência e acesso a todos principalmente no âmbito escolar. Trata-se de uma forma de fazer valer aquilo que foi 
reconhecido e discriminado como garantia das leis que mantêm ou regulam a vida em sociedade de todos os sujeitos com deficiência.

Os direitos humanos asseguram o processo de educar promovido e enfatizado não apenas como direito, e sim uma promoção do cumprimento do dever de todos. Nessa perspectiva entende-se que atos de truculência não podem mais serem permitidos, pois a ética $\mathrm{e}$ as leis não permitem que determinadas atitudes inumanas sejam praticadas por qualquer pessoa contra alguém que se encontre menos favorecido, mesmo aqueles que não têm nenhuma deficiência específica.

Os direitos inerentes aos seres humanos devem ter o propósito de buscar a permanência da impassibilidade social, como forma de garantir aos mesmos o direito de permanecer e usufruir de forma análoga dentro de um estado democrático. Tem-se o intuito de que haja o conhecimento de quais são esses direitos, para que possam ser cobrados e efetivados dentro da sociedade ao qual venham pertencer. Desse modo, percebe-se a grande ação que a educação proporciona no que se refere à autonomia destes indivíduos.

De acordo com Bobbio (2013, p. 12):

Sabemos hoje que também os direitos ditos humanos são o produto não da natureza, mas da civilização humana; enquanto direitos históricos, eles são mutáveis, ou seja, suscetíveis de transformação e de ampliação. Basta examinar os escritos dos primeiros jusnaturalistas para ver quanto se ampliou a lista dos direitos: Hobbes conhecia apenas um deles, o direito à vida. Como todos sabem, o desenvolvimento dos direitos do homem passou por três fases: num primeiro momento, afirmaram-se os direitos de liberdade, [...] num segundo momento, foram promulgados os direitos políticos, [...] finalmente, foram proclamados os direitos sociais, que expressam o amadurecimento de novas exigências - podemos dizer de novos valores [...] (BOBBIO, 2013, p. 32).

Esses direitos são inerentes de todos os seres humanos, perpassando por todos aqueles indivíduos que venham em algum momento de sua vida deles necessitar. Quando enfatizada a noção de seres livres perante a Constituição Federal e não se busca os direitos, acaba-se indo de encontro a algo que já tenha sido enfatizado há vários anos, e se esquece de buscar sua efetivação por esse reconhecimento de forma de igualdade de acesso e permanência de qualquer indivíduo no meio social do qual deseje participar.

Leal (2015, p. 154) corrobora, afirmando que:

Os direitos humanos são pervertidos no exato momento em que se tomam objeto de tratamento jurídico, pois, concebidos historicamente como um mecanismo de proteção dos cidadãos livres contra o arbítrio dos governantes [...] eles são esvaziados na medida em que é o próprio Estado que os regulamenta. 
Quando não se considera os direitos humanos como algo constitutivo da humanidade, esses direitos deixam de ser reconhecido e tratado apenas como algo natural dos sujeitos, para se tornarem objetos de troca entre governo e população. Assumido na perspectiva do Estado, torna-se algo que necessite do poder judiciário para que venha ser reconhecido e oferecido a todos (LEAL, 2015). Na verdade por ser de direito de todos não poderia estar sendo tratado como mecanismo de disputa entre poderes, uma vez que é inerente do ser humano.

Ao serem mencionados alguns direitos como forma de igualdade entre a humanidade, pode-se observar que fatores como os sociais e individuais de liberdade, de segurança e relacionados ao bem-estar e ao desenvolvimento como também a igualdade, fizeram com que os seres humanos ao se sentirem infligidos em alguns de seus direitos, buscassem assegurar aquilo que está sendo desfavorecido em função de uma prática irregular imposta por pessoas, órgãos, ou entidades como forma desrespeitosa naquilo que foi assegurado como de direito a todos.

Os direitos humanos têm base democrática, e atualmente contribuem para um maior significado e respeito a toda a população, buscando constante concretização de toda forma de direito como sendo constitucionalmente legal como se vê a seguir:

\footnotetext{
Pode-se dizer que a Constituição Federal de 1988 alargou a abrangência dos direitos e garantias fundamentais e desde o seu preâmbulo prevê um Estado Democrático de Direito no país, objetivando o exercício dos direitos sociais e individuais, a liberdade, a segurança, o bem-estar, o desenvolvimento, a igualdade e a justiça, como valores supremos de uma sociedade fraterna, pluralista e sem preconceitos. A prevalência dos direitos humanos é um princípio que deve nortear a Constituição e o desenvolvimento do Brasil (LEAL, 2015, p. 131).
}

Observa-se dessa forma, que a educação através de sua prática pode contribuir nesse processo de reconhecimento e concretização do acesso legal a todas as formas de direitos legais a todos os seres humanos. No Brasil, os direitos humanos estão cada vez mais tendo sua efetivação por via judicial, desconhecendo assim o mesmo como inerente a todo cidadão. Esse processo está sendo viabilizado via educação, como forma de conscientização de todos os cidadãos para poder reconhecer e buscar serem éticos, e de fato exigir que os direitos humanos possam ser efetivados (LEAL, 2015).

$\mathrm{Na}$ prática o processo educacional possibilita habilidades para a formação e conscientização dos sujeitos no que se refere à busca de seus direitos, fazendo assim com que 
estes se tornem pessoas com uma formação capaz de se preocuparem com a paz e o processo de solidariedade mundial. De modo específico, a maneira de construir uma escola inclusiva na qual todos possam se sentir reconhecidos, valorizados e respeitados envolve cuidar dos conteúdos ensinados e do modo como a matéria é transmitida (STAINBACK e STAINBACK 2008). Nesse sentido, a escola inclusiva precisa ser compassiva aos anseios de alguns alunos de identificar com outros que possam compartilhar características e interesses semelhantes (STAINBACK e STAINBACK 2008).

Por esta razão a inclusão escolar não é somente colocar crianças com deficiência no ensino regular sem suporte, porque não há como se programar procedimentos de inclusão que visem oferecer escolarização de qualidade, sem efetivos serviços de apoio ao trabalho do educador nas escolas regulares Silva (2015).

De fato há uma necessidade de manter o serviço de educação especial. De acordo com o posicionamento de Silva (2015), é na educação especial que se vai encontrar os profissionais para fazer a passagem dos professores do ensino regular para a educação inclusiva. A autora entende que o professor de educação especial precisa dá um passo maior e que saia da sua própria especialidade, para ajudar o professor de ensino regular a atuar junto com as crianças com deficiência.

Para Silva (2015), é necessário promover uma avaliação das reais condições do sistema de ensino, a fim de que a inclusão ocorra de forma gradativa, contínua, sistemática e planejada. Dessa forma, a mobilização continua sendo cobrada, pela defesa de direitos de todos no processo da inclusão social, buscando uma participação de toda a população cada vez mais inserida e inclusa dentro do processo de ensino-aprendizagem.

\section{CONSIDERAÇÕES FINAIS}

A inclusão vem ao longo dos tempos perpassando por inúmeras mudanças, essas no tocante a efetivação de algumas políticas públicas inclusivas. Ao se reportar a educação inclusiva observamos que sua concretização ainda continua a ser desempenhada de forma gradativa, isso prejudicando e ocasionando o retrocesso no processo de desenvolvimento de todos aqueles que precisam da inclusão para obter, e conseguir superar alguns déficits ocasionados pela deficiência. 
Ao longo dos tempos a inserção das pessoas que tinham alguma deficiência nos diversos espaços sociais foi sendo conquistado, porém é observável que esse processo precisa ganhar melhores formatos, para assim poder desenvolver e incluir de forma condizente com cada realidade.

Esses sujeitos vem desde os primórdios da civilização buscando igualdade e condições nos diversos espaços, sendo o contexto escolar um espaço de grande importância, isso é devido que esse ambiente podem possibilitar uma autonomia na vida de todos, como também um aprendizado significativo a cada um, e assim possibilitando juntamente a todos uma igualdade através de possibilidades que forem ofertadas as essas pessoas de poderem se sentir pertencente e usufruir de forma igualitária a todos os espaços, e dessa forma se sentir como as outras pessoas sem nenhuma deficiência específica.

A educação oferecida no Brasil ainda deixa muito a ansiar, isso é percebido através dos dados científicos sobre a população deficiente, mostrando que a inclusão ainda é um anseio do futuro, mostrando que muitas pessoas deficientes ainda continua sendo desassistidas pelas diversas políticas públicas existente no país.

E dessa forma levando a diversos questionamentos do papel da população para que esse quadro possa mudar. Diante de algumas garantias, esses direitos ainda continuam sendo negados, levando a uma grande parcela da população não conseguirem o tão sonhado progresso nos défices ocasionados a elas pela deficiência, e assim colocando uma falsa ideia que não existe aprendizado para aqueles com deficiência.

Portanto se faz necessário novas reformulações, e uma necessidade imensa de grandes investimentos e capacitações no que se refere a educação inclusiva. Uma vez que é através da educação que será possível mudar esse quadro, e possibilitar a essas pessoas com deficiência uma vida plena e digna no que se refere as condições de igualdade em todos os conhecimentos ofertados.

Dessa forma, o caminho percorrido para se almejar a inclusão ainda é algo não acessível a todos no Brasil, necessitando assim de maiores investimentos e uma maior efetivação das políticas no processo inclusivo. Já que mesmo existindo leis, essa situação ainda é hipotética em grandes contextos do pais, podendo assim através da educação e igualdade dessa ofertar, se chegar ao tão esperado momento em que será destacado que todas 
as pessoas com deficiência é assistida por alguma política pública, e dessa forma podendo garantir uma melhor autonomia na vida futura de cada um.

\section{REFERÊNCIAS}

BRASIL. MEC. Lei de Diretrizes e Bases da Educação Nacional, LDB 9.394 de 20 de dezembro de 1996.

BOBBIO. N. Democracia, direitos humanos, guerra e paz / Giuseppe Tosi (Org.) - v.I. João Pessoa: Editora da UFPB (2013).

BORDIEU. P. Escritos de Educação. Petrópolis: Vozes. I5 ${ }^{\text {a }}$ Ed. (2014).

Carvalho, R. E. Educação inclusiva: com os pingos nos “is". 13 $3^{\mathrm{a}}$. ed. Porto Alegre: Mediação (2019).

DINIZ. D. O que é deficiência? Rio de Janeiro: Brasiliense Coleção Primeiros Passos (2012).

FREIRE, P. Educação e mudança. Rio de Janeiro: Paz e Terra. 36a․ Ed. (2014).

JANNUZZI, G. A educação do deficiente no Brasil: dos primórdios ao início do século XXI. Campinas, SP: Autores Associados (2017).

LEAL, R. G. Direitos Humanos no Brasil: desafios à democracia. Porto Alegre: Livraria do Advogado; Santa Cruz do Sul: Edunisc (2015).

MARTINS e TAVARES. S. V. 1. M e H. M. A família e a escola: desafios para a educação no mundo contemporâneo. Revista da Católica, Uberlândia, v. 2, n. 3, p. 256263, (2010).

MEKSENAS, P. Sociologia da Educação: Uma introdução ao estudo da escola no processo de transformação social. São Paulo: Cortez (2017).

MORAES, A.P.; OLIVEIRA, G.F. Educação Especial: Perspectivas e Práticas pedagógicas no contexto Escolar. Id on Line Revista Multidisciplinar e de Psicologia, Janeiro de (2017), vol.ro, n.33, p.I4I-I52. ISSN: I981- II79. Disponível em: https://idonline.emnuvens.com.br/id/article/view/607/87o. Acesso em ro de janeiro de 2020.

OlIVEIRA, I. A. (2015). Desafios da didática diante das políticas de inclusão. Crítica Educativa (Sorocaba/SP), (2015). Vol.I, n.2, p. IIo-I26, Jul./dez, ISSN: 2447-4223. Disponível em:

http://www.criticaeducativa.ufscar.br/index.php/criticaeducativa/article/view/36/19I.

Acesso em o4 de fevereiro de 2020. 
ONU. Organização das Nações Unidas. Declaração Universal dos Direitos Humanos. Paris (1948).

RODRIGUES, J. M. C. Pessoas com síndrome de down: uma reflexão para pais e professores. Rio de Janeiro: Wak Editora (2015).

SILVA, T. V. Inclusão escolar: relação família-escola. V seminário internacional sobre profissionalizante, (2015). Disponível

em:

https://educere.bruc.com.br/arquivo/pdf2015/16662_8048.pdf.

STAINBACK, S. e STAINBACK, W. Inclusão: um guia para educadores. Trad. Magda França Lopes. Porto Alegre: Editora Artmed. Reimpressão (2008). 